\title{
A Web-Based Study of Differences in Jordanian People's Knowledge and Attitudes toward COVID-19
}

\author{
Nijmeh AL-Atiyyat ${ }^{1}$, Sami Al-Rawashdeh ${ }^{{ }^{*}}$, Majd T Mrayyan ${ }^{1}$
}

${ }^{1}$ The Hashemite University, JORDAN

*Corresponding Author: samiy@hu.edu.jo

Citation: AL-Atiyyat N, Al-Rawashdeh S, Mrayyan MT. A Web-Based Study of Differences in Jordanian People's Knowledge and Attitudes toward COVID-19. Electron J Gen Med. 2021;18(6):em318. https://doi.org/10.29333/ejgm/11209

\section{ARTICLE INFO}

Received: 24 May 2021

Accepted: 25 Aug. 202

\section{ABSTRACT}

Background: Coronavirus disease-19 (COVID-19) is a worldwide public health issue. Adequate knowledge, a positive attitude, and appropriate control of COVID-19 are essential to eradicate the disease. People's knowledge of and attitudes toward COVID-19 should be analyzed and explained; this helps decision-makers understand the general public knowledge about the disease. The attitudes of the general public are necessary to implement measures to stop the spread of the disease. Thus, this study aimed to describe people's knowledge about and attitudes toward COVID-19 and compare both concepts based on subjects' characteristics.

Methods: This cross-sectional web-based survey was conducted in January 2021. The snowball sampling method was used.

Results: A total of 281 adult subjects participated in this study. Most participants demonstrated good knowledge and a positive attitude ( $80.5 \%$ and $77.11 \%)$ towards the COVID-19, respectively. Better knowledge about COVID-19 was among older age, females, and highly educated subjects. A significantly positive attitude towards the COVID19 was among married subjects and subjects who had health insurance.

Conclusions: The findings are relevant for the evaluation of the knowledge and attitudes of the general public. Knowledge is a crucial factor for shaping people's attitudes, but this is influenced by various factors related to people's knowledge and attitudes. Thus, continuous and updated learning efforts are still required from the overall public. This study provided valuable insights into how public health initiatives can better protect the population's health during public health emergencies.

Keywords: COVID-19, knowledge, attitude, Jordan, web-based survey

\section{INTRODUCTION}

Coronavirus is a huge family of respiratory viruses that cause Acute Respiratory Syndrome [1,2]. The current outbreak is caused by strains of coronavirus that were not detected in the world before the explosion of Wuhan, China, in December 2019. Coronavirus disease-19 (COVID-19) causes most people's mild disease, but it can make some people very sick [3] and may lead to death. Seniors and those with pre-existing medical conditions (such as hypertension, heart problems, obesity, or diabetes) seem to be more fragile [4].

COVID-19 has high transmittance [5]. There is still some uncertainty in the mechanism of viral infection in COVID-19; however, human-to-human transmission has been reported through respiratory droplets and aerosols caused by direct contact with infected individuals and contaminated bodies [2]. World Health Organization (WHO) declared it an epidemic on March 12, 2020, and called for global efforts to stop its further spread. Different countries worldwide adopted different preventive and control measures at different levels to combat the COVID-19 epidemic [6].
In Jordan, almost four months after the disease's onset, the virus's first confirmed case was recorded inside the country on March 2, 2020, by public officials Jordanian Ministry of Health $(\mathrm{MOH})$. The source of the virus was linked to Italy [7]. Around the end of January 2021, there were more than $(320,453)$ confirmed COVID-19 cases in Jordan, with (4224) confirmed deaths [8]. The Government of Jordan has also taken numerous measures to regulate the spread of COVID-19 transmission. Measures included the initial closing of public spaces, tourism, educational institutions, and business organizations. The current government's particular policy measure is a sensible lockdown that the WHO officials appreciated. First, the $\mathrm{MOH}$ used the media to educate the public about the disease, its transmission mode, the importance of social distancing, washing hands, using disinfectants, home hygiene, and advising people to avoid any gatherings. Then, the Jordanian Government applied a nationwide lockdown and activated the Defense Law, which allows the army and police to ensure public adherence to the curfew. Vaccines are one of the most reliable and cost-effective public health interventions ever implemented to save millions of lives each year [5,9-11]. However, with the new strains of the virus and until the full benefits of the COVID-19 vaccine have been utilized the preventive measures and guidelines are 
crucial. The important thing is that the success of any strategy to combat COVID-19 relies heavily on the general public's adherence to the guidelines issued by the relevant authority [12].

The existing literature has indicated that knowledge and attitude concerning infectious diseases are significantly correlated with protective behavior $[5,6,9]$. Therefore, the behaviors of the general public and other people in potential risk groups can play a huge role in both the prevention and control of infectious diseases $[9,13]$. Therefore, it is essential to assess the public's knowledge and attitudes regarding COVID19. However, little is understood about the knowledge and attitudes among the Jordanian public regarding COVID-19. Specifically, this study was conducted to evaluate knowledge and attitudes among the Jordanian public and to assess potential influencing factors associated with preventive behaviors. The study results can provide information about the effectiveness of the health education efforts of health authorities in Jordan and how to design evidence-based interventions to scale back the danger of contracting COVID-19. Recent studies on COVID-19 revealed that knowledge $[5,9,13]$ might account for the precautionary actions of the general public. In addition, the results of previous studies revealed that a better level of knowledge is positively associated with the practice of preventive measures [13-18], and attitudes also associate positively with preventive behaviors [9,13-18].

Thus, the massive challenge it entails for global health and economics, ordinary people's knowledge of and attitudes toward COVID-19 should be analyzed and explained; this helps decision-makers understand the general public knowledge of and attitudes toward the disease $[5,13]$. Therefore, this study aimed to describe people's knowledge about and attitudes toward COVID-19 and compare both concepts based on subjects' characteristics of age, gender, marital status, education level, income, and health insurance status.

\section{METHODS}

\section{Design and Sample}

This is a secondary analysis of large-scale cross-sectional data collected from subjects using a web-based survey recruited through convenience snowballing sampling. Jordanian adult subjects were invited to participate through social media, including Facebook and Whatsapp. Subjects were recruited if they were willing to participate, read and write Arabic, and had access to the Internet.

\section{Measures}

We collected subjects' sociodemographic characteristics (i.e., age, gender, marital status, level of education, income level, and health insurance) and questionnaires on the knowledge about and attitudes toward COVID-19. The face validity of these tools was checked by three PhD-prepared nurses who agreed that the items appeared to be appropriate and relevant to what they intend to measure.

\section{Knowledge about COVID-19}

A scale consisting of 18 items was used to measure the knowledge about the COVID-19. The research team developed the items based on a literature review and the previous studies measuring knowledge about COVID-19 [13-18]. These items covered knowledge of the signs and symptoms, transmission, prevention, and treatment of COVID-19. The responses of the items were "true," "false," or "I do not know," with one point was given for each correct answer and 0 points given for either incorrect answer or the "I do not know" response. Thus, the total score of this scale was the total number of correct answers, and in turn, the total scores could range between 0 to 18; higher scores indicated a higher level of knowledge. The Cronbach's reliability alpha for the knowledge scale was 0.73 .

\section{Attitudes toward COVID-19}

A 6-item scale was used to measure the attitudes toward COVID-19, especially data on attitudes toward guidelines for preventing COVID-19, governmental measures and directions, and people's role in controlling the virus. The scale items were adapted from previous studies in the COVID-19 context $[13,14,18]$. The items asked participants regarding their level of agreement "Do you agree with the following statements" with the six items statements. The responses designed on a 5-Likert scale ranged " 1 " = strongly disagree and " 5 "=strongly agree. The total scores calculated by summing the items' responses ranged from 6 to 30; higher scores indicated positive attitudes toward COVID-19. The Cronbach's reliability alpha for the attitudes scale was 0.76 .

\section{Procedures and Human Protection}

Before collecting the data, the ethical approval for this study was granted by The Hashemite University- Jordan. The subjects were asked to answer the survey (informed consent) or decline to participate in the study (finish the survey without collecting any data). The data were collected using a webbased survey prepared with the Google platform. The survey was distributed to the public through multiple social media platforms, including Facebook and WhatsApp. Voluntary participation and answering any questions were assured as the survey was designed to skip a question. No identifiable personal information was collected. The responses were stored in the principal investigator's Google Drive and personal computers that were password-protected. Data were collected over the last ten days of January 2021. As it was a snowball conscience sampling, subjects were also invited to share the survey link to their contacts. After four days to the potential subjects, a reminder was announced, whereas we emphasized subjects to take the survey once.

\section{DATA ANALYSIS}

The Statistical Package for the Social Sciences (SPSS) version 25 was used in analyzing the data. A significance level of $\leq .05$ was used. Subjects' characteristics and subjects' scores on individual items on knowledge about and attitudes toward COVID-19 were described with mean and standard deviations or frequencies and percentages, as appropriate to the measurement level. Bivariate Pearson's correlation coefficient was used to examine the association between age and total scores on knowledge about and attitudes toward COVID-19. Independent samples t-test was used to examine differences in subjects' knowledge about and attitudes toward COVID-19 scores for variables with two categories, while a One-way ANOVA test was used for variables with more than two categories. 
Table 1. The subjects' scores on the knowledge about and attitudes toward COVID-19 according to their sociodemographic and clinical characteristics $(\mathrm{N}=281)$

\begin{tabular}{|c|c|c|c|c|c|}
\hline \multirow[t]{2}{*}{ Characteristics } & \multirow{2}{*}{$\begin{array}{c}\text { Total sample } \\
\text { Mean } \pm \mathrm{SD}^{\star} \text { or } n(\%)\end{array}$} & \multicolumn{4}{|c|}{ Characteristics association's with } \\
\hline & & $\begin{array}{c}{ }^{\text {E} K n o w l e d g e ~ t o t a l ~} \\
\text { scores }\end{array}$ & p-value & ${ }^{\text {EAttitudes total scores }}$ & p-value \\
\hline Age, years & $27.45 \pm 11.07$ & $r=0.131$ & 0.028 & $r=0.091$ & 0.130 \\
\hline \multicolumn{6}{|l|}{ Gender } \\
\hline Male & $83(29.53)$ & $13.95 \pm 3.12$ & \multirow{2}{*}{0.039} & $24.34 \pm 3.71$ & \multirow{2}{*}{0.389} \\
\hline Female & $198(70.47)$ & $14.75 \pm 2.44$ & & $24.73 \pm 3.25$ & \\
\hline \multicolumn{6}{|l|}{ Marital status } \\
\hline Single/Widow/divorced & $200(71.17)$ & $14.31 \pm 2.71$ & \multirow{2}{*}{0.105} & $24.41 \pm 3.34$ & \multirow{2}{*}{0.048} \\
\hline Married & $81(28.83)$ & $15.01 \pm 2.53$ & & $25.13 \pm 3.48$ & \\
\hline \multicolumn{6}{|l|}{ Level of education } \\
\hline$\leq$ high school & $30(10.67)$ & $13.53 \pm 2.75$ & \multirow{2}{*}{0.033} & $25.46 \pm 3.9$ & \multirow{2}{*}{0.148} \\
\hline >high school & $251(89.33)$ & $14.63 \pm 2.65$ & & $24.51 \pm 3.32$ & \\
\hline \multicolumn{6}{|l|}{ Monthly income, USD } \\
\hline$<420$ & $64(22.77)$ & $14.01 \pm 3.04$ & \multirow{5}{*}{0.089} & $27.73 \pm 3.92$ & \multirow{5}{*}{0.945} \\
\hline $421-700$ & $93(33.09)$ & $14.27 \pm 2.81$ & & $24.63 \pm 3.82$ & \\
\hline $701-1120$ & $66(23.48)$ & $14.66 \pm 2.5$ & & $24.71 \pm 2.65$ & \\
\hline $1121-1400$ & 32 (11.38) & $15.12 \pm 2.15$ & & $24.65 \pm 2.71$ & \\
\hline$>1400$ & $26(9.25)$ & $15.46 \pm 1.92$ & & $24.07 \pm 2.91$ & \\
\hline \multicolumn{6}{|l|}{ Health insurance } \\
\hline No & $84(29.89)$ & $14.46 \pm 2.38$ & \multirow{2}{*}{0.833} & $23.94 \pm 3.56$ & \multirow{2}{*}{0.028} \\
\hline Yes & $197(70.11)$ & $14.53 \pm 2.8$ & & $24.9 \pm 3.28$ & \\
\hline
\end{tabular}

*M \pm SD; mean \pm standard deviation, $£=$ Data presented as mean \pm standard deviation or as Pearson's correlation coefficient ( $r$ ); Independent samples t-test was used to examine differences in scores for variables with 2 categories while One-way ANOVA test was used for variables with $>2$ categories

\section{RESULTS}

\section{Sample Characteristics}

A total of 281 subjects participated in this study. The majority of subjects were female, married, highly educated, had a monthly income between 421 and 700 USD, and had health insurance. The detailed characteristics of the subjects are presented in Table 1.

\section{Subjects' Characteristics Relations with Knowledge and Attitudes towards COVID-19}

Table 1 also shows the associations between subjects' characteristics and their scores on knowledge about and attitudes towards COVID-19. The age had a weak although a significant positive association with knowledge about COVID19 but not with attitudes towards COVID-19. The association indicated that as age increases, the subjects' knowledge about COVID-19 tends to increase. Similarly, gender and education level had significant associations with knowledge about but not with attitudes towards COVID-19. The associations indicated that females and highly educated subjects had higher total scores on knowledge about COVID-19.

Marital status and health insurance showed significant association with attitudes towards COVID-19 but not with the knowledge; in a way, married subjects and subjects with health insurance had significantly higher scores on attitudes towards COVID-19. Monthly income did not show significant associations with both knowledge about and attitudes towards COVID-19.

\section{Knowledge about COVID-19}

The subjects answered on average $14.5( \pm 2.68)$ out of the 18 items correctly (Table 2). Most subjects had answered the knowledge items correctly using the scale's level, with the range of correct answers ranging between $35.2 \%$ to $96.1 \%$. The lowest percentage of the correct answer was for the item asking about the duration of protection that the natural active immunity (being infected with COVID-19) can offer to the infected individual. "The body of the infected individuals with COVID-19 may develop immunity that protects them for 3-12 months only," while the highest was for the question "isolation and treatment of people who are infected with the COVID-19 virus are effective ways to reduce the spread of the virus". The detailed description of the items and the responses are presented in Table 2.

\section{The Attitudes toward COVID-19}

A high percentage of subjects showed positive attitudes toward COVID-19 on the individual items (Table 3). The highest percentage of a positive attitude toward COVID-19 was for the item of "I fear infection for myself and my family." The lowest percentage of a positive attitude toward COVID-19 was that the item of "regulations taken by the government is enough to combat disease." In concordance with the individual items, subjects had a mean score of 24.6 out of 30 on the attitude scale, indicating they had a relatively high positive attitude toward COVID-19. In addition, the mean scores of individual items of the scale indicated that the majority of respondents were in the "agree" or "strongly agree" categories. The detailed description of the attitude scale items and the subjects' responses are presented in Table 3.

We conducted further analysis to examine whether the attitudes questionnaire's individual items score differs according to the subjects' sociodemographic characteristics of gender, marital status, education level, and health insurance using independent samples t-test and according to the subjects' income using One-way ANOVA test. The results of the analyses indicated that most of the items did not differ according to the subjects' characteristics except for the following items: item 5, "I am willing to follow the provided precautions to control the virus," in which the males had lower scores than females $(4.36 \pm 0.84$ vs $4.58 \pm 0.65, t(124.503)=-2.155$, $\mathrm{p}=0.033$ ); item 2 "I pay close attention to the development of the epidemic situation" in which single subjects scored lower than married subjects $(3.75 \pm 0.91$ vs $4.01 \pm 0.84, \mathrm{t}(279)=-2.221$, 
Table 2. Subjects total scores and individual items on knowledge about COVID-19 (N=281)

\begin{tabular}{|c|c|c|c|}
\hline No & Item & Incorrect & Correct \\
\hline & & $\mathbf{n}(\%)$ & $\mathbf{n}(\%)$ \\
\hline 1 & $\begin{array}{c}\text { The main clinical symptoms of COVID-19 are fever, fatigue, dry cough, loss of smell and/or taste [35], and } \\
\text { muscle pain [18]. }\end{array}$ & $12(4.3)$ & $269(95.7)$ \\
\hline 2 & $\begin{array}{l}\text { Unlike the common cold, stuffy nose, runny nose, and sneezing are less common in persons infected with the } \\
\text { COVID-19 virus [18]. }\end{array}$ & $85(30.2)$ & $196(69.8)$ \\
\hline 3 & $\begin{array}{l}\text { There currently is no effective cure for COVID-2019, but early symptomatic and supportive treatment can help } \\
\text { most patients recover from the infection [18]. }\end{array}$ & $59(21.0)$ & $222(79.0)$ \\
\hline 4 & $\begin{array}{l}\text { Not all persons with COVID-2019 will develop severe cases. Only those who are elderly, have chronic illnesses, } \\
\text { and are obese are more likely to be in severe cases [18]. }\end{array}$ & $121(43.1)$ & $160(56.9)$ \\
\hline 5 & Persons with COVID-2019 cannot infect others with the virus when they do not have a fever (13). (Reworded) & $69(24.6)$ & $212(75.4)$ \\
\hline 6 & $\begin{array}{l}\text { The COVID-19 virus is highly infectious and spreads quickly via the respiratory droplets of infected individuals } \\
{[18] . \text { (Reworded) }}\end{array}$ & $29(10.3)$ & $252(89.7)$ \\
\hline 7 & $\begin{array}{l}\text { It is not necessary for all people including children and young adults to take measures to prevent the infection } \\
\text { by the COVID-19 virus [18]. (Reworded) }\end{array}$ & $31(11.0)$ & $250(89.0)$ \\
\hline 8 & $\begin{array}{c}\text { To prevent the infection by COVID-19, individuals should avoid going to crowded places such as public } \\
\text { transportations [18]. }\end{array}$ & $26(9.3)$ & $255(90.7)$ \\
\hline 9 & $\begin{array}{l}\text { Isolation and treatment of people who are infected with the COVID-19 virus are effective ways to reduce the } \\
\text { spread of the virus [18]. }\end{array}$ & $11(3.9)$ & $270(96.1)$ \\
\hline 10 & Washing hands frequently, wearing medical masks and other measures can effectively prevent infection [14]. & $16(5.7)$ & $265(94.3)$ \\
\hline 11 & The incubation time of the disease is up to 14 days, typically $3-7$ days [14]. & $40(14.2)$ & $241(85.8)$ \\
\hline 12 & COVID-19 may lead to pneumonia, respiratory failure [17], and death (added by the PI's). & $26(9.3)$ & $255(90.7)$ \\
\hline 13 & In the control of COVID-19, Foods with Vitamin B and C [15]. (Reworded) & & $239(85.1)$ \\
\hline 14 & It is possible that COVID-19 could spread without showing sym & & \\
\hline 15 & Antibiotics can prevent or kill the coronavirus [16]. & $104(37.0)$ & $177(63.0)$ \\
\hline 16 & Smoking can prevent or kill the coronavirus. (PI's Item) & $59(21)$ & $222(79.0)$ \\
\hline 17 & $\begin{array}{l}\text { The body of the infected individuals with COVID-19 may. develop immunity that protects them for 3-12 } \\
\text { months only. (PI's Item) }\end{array}$ & $182(64.8)$ & $99(35.2)$ \\
\hline \multirow[t]{3}{*}{18} & Preventive measures against COVID-19 include frequently cleaning and disinfecting surfaces [17] & $34(12.1)$ & $247(87.9)$ \\
\hline & Total (mean) & $54.39(19.35)$ & $226.6(80.6)$ \\
\hline & Individuals mean scores (correct answers out of 18) & 14.51 & \pm 2.68 \\
\hline
\end{tabular}

Table 3. Subjects total scores and individual items on attitudes towards COVID-19 ( $N=281)$

\begin{tabular}{|c|c|c|c|c|c|c|c|c|}
\hline \multirow[t]{2}{*}{ No } & \multirow[t]{2}{*}{ Item } & \multicolumn{2}{|c|}{ Disagree } & \multicolumn{2}{|c|}{ Neutral } & \multicolumn{2}{|c|}{ Agree } & \multirow{2}{*}{ Items $\mathbf{M} \pm \mathbf{S D}^{\star}$} \\
\hline & & $\mathbf{n}$ & $\%$ & $\mathbf{n}$ & $\%$ & $\mathbf{n}$ & $\%$ & \\
\hline 1 & $\begin{array}{l}\text { The world including Jordan can win the battle against the } \\
\text { COVID-19 virus? [18] }\end{array}$ & 6 & 2.1 & 42 & 14.9 & 233 & 82.9 & $4.14 \pm .74$ \\
\hline 2 & $\begin{array}{l}\text { I pay close attention to the development of the epidemic } \\
\text { situation [14]. }\end{array}$ & 25 & 8.9 & 59 & 21.0 & 197 & 70.1 & $3.82 \pm .90$ \\
\hline 3 & I play an important role in controlling the epidemic [14]. & 10 & 3.6 & 49 & 17.4 & 222 & 79.0 & $4.11 \pm .85$ \\
\hline 4 & I fear infection for myself and my family [14]. & 5 & 1.8 & 15 & 5.3 & 261 & 92.9 & $4.60 \pm .68$ \\
\hline 5 & $\begin{array}{c}\text { I am willing to follow the provided precautions to control the } \\
\text { virus. (PI's Item) }\end{array}$ & 4 & 1.4 & 20 & 7.1 & 257 & 91.5 & $4.51 \pm .72$ \\
\hline \multirow[t]{3}{*}{6} & $\begin{array}{l}\text { Regulations taken by the Government are enough to combat } \\
\text { disease [17]. }\end{array}$ & 57 & 20.3 & 94 & 33.5 & 130 & 46.3 & $3.40 \pm 1.06$ \\
\hline & Total scores (possible range 6-30) & -- & -- & -- & -- & -- & -- & $24.61 \pm 3.39$ \\
\hline & Average of each categories & 17.83 & 6.35 & 46.5 & 16.53 & 216.67 & 77.11 & -- \\
\hline
\end{tabular}

${ }^{\star} \mathrm{M} \pm \mathrm{SD} ;$ mean \pm standard deviation

$\mathrm{p}=0.027)$ and those who had no insurance scored lower than insured subjects $(3.45 \pm 0.91$ vs $3.94 \pm 0.87, t(279)=-3.433$, $p=0.001$ ); and item 6 "regulations taken by the government are enough to combat disease" in which subjects with education level of high school or less had higher scores than subjects who had higher than high school level of education $(3.80 \pm 0.91$ vs $3.36 \pm 1.05, t(279)=2.132, p=0.034)$.

\section{DISCUSSION}

The COVID-19 pandemic has had a devastating impact worldwide, which prompted mitigation policies to contain the pandemic $[2,6,14]$. The bottom strategy followed by most countries worldwide was to scale back the transmissibility of the disease, often by non-pharmaceutical interventions, including enforcing masks policy, hand sanitization, social distancing, travel restrictions, schools' closures, and partial or complete lockdowns $[6,12]$. At the start of the pandemic, a comparatively small number of confirmed cases in Jordan attributed to government measures. However, recent confirmed cases are worrying.

The sample of 281 subjects who participated in this study was mainly well-educated, with females predominating. The skewed in the sample toward females and well-educated participants have also been seen in previous studies in Jordan $[19,20]$ and Saudi Arabia [21]. In general, the education enrollment rate for females in Jordan is higher than for males. These data reflect the Jordanian woman's awareness and awareness of the value and importance of education. The vast majority of participants were below 30 years, representing the generally younger Jordanian population [22]. Similarly, 
females [21] and highly educated subjects were predicted and consisted of previous studies comparing the overall population's knowledge with higher education levels. The latter would have far better knowledge [5,19,21,23-26].

A positive attitude about the COVID-19 pandemic was among married subjects; this finding is analogous to other studies with higher knower, attitudes, and practices among married subjects [14,24-28]. This positive attitude might be because married people have the responsibility of caring for their families and self-protection. Therefore, they tend to find out more about protection, have a more positive attitude, and interact in proactive protective actions.

Also, subjects who had health insurance had significantly higher scores on attitudes towards COVID-19. This result is in line with a vast body of research that yields broadly consistent and significant findings of the relationship between health insurance and health-related outcomes [24-26,28]. Thus, health insurance improved the likelihood of appropriate care and is likely to result in the more exceptional and more appropriate use of health services. Health insurance appears to achieve these positive effects by facilitating ongoing care with a regular healthcare provider and reducing financial barriers to obtaining those services. That contributes to appropriate care; having insurance plays a role in enhancing efficacy beliefs, which had a significant and robust impact on practicing preventive behaviors, implying that promoting preventive behaviors toward COVID-19 would promote efficacy beliefs. This result is consistent with evidence that efficacy belief is a significant predictor of preventive behaviors [5,14,29].

\section{Knowledge about COVID-19}

Generally, the respondents' knowledge was adequate (total knowledge score 14.5 out of 18). It validates that the respondents have adequate knowledge about COVID-19. This result coincides with similar studies in Jordan and abroad [5,12-15,17-19,24-27]. The result was expected because the government in Jordan at all levels has released relevant education materials and has delivered COVID-19-related content through various channels, including television, the Internet, and publicity boards.

The vast majority of respondents had excellent knowledge about the required measures to prevent the disease. This result may be credited to the subjects' characteristics because significant associations between these demographics and knowledge and attitudes towards COVID-19 were verified in the present study.

On the one hand, the more scientific question related to the duration of protection that the natural active immunity can offer to the infected individual was correctly answered by few respondents. On the other hand, somehow, this result might be accepted as it required some professional background however, it implies that the public has incomplete knowledge of COVID-19, especially regarding some expert topics, and still needs further education.

\section{The Attitudes toward COVID-19}

Relatively, subjects had a high positive attitude toward COVID-19 with a mean score of 24.6 out of 30 on the attitude scale. These results are similar to those of other published studies [5,12-19,24-27,30], likely because the government in Jordan has devoted serious standing to the epidemic and adopted strict prevention and control measures promptly against the disease after the outbreak. Moreover, with the
COVID-19 pandemic and media reports, the public in Jordan understands the severity of the epidemic. In turn, they desire to participate in epidemic prevention and control activities. Also, the exceptional knowledge about COVID-19 among the Jordanians can explain this result. It is imperative to say that higher COVID-19 knowledge scores were found to be strongly associated with a lower possibility of negative attitudes and potentially dangerous practices towards the COVID-19 epidemic in this study. These findings indicate the importance of improving public' COVID-19 knowledge by health education and improving their attitudes towards COVID-19.

The findings of this study concerning the demographic characteristics associated with knowledge and attitude towards COVID-19 are generally consistent with previous studies [5,31]. However, these findings propose that the health education intervention would be more functioning if it targets specific demographic characteristics; for example, the COVID19 knowledge may significantly increase if the health education programs are specifically designed for men with a low education level with no insurance.

The highest percentage of a positive attitude toward COVID-19 was for the item of "I fear infection for myself and my family." indicating that health authorities should continue to organize corresponding health education campaigns to prevent fear of the spreading of COVID-19. This result is consistent in particular with previous studies [24-26,30,32].

The lowest percentage of a positive attitude toward COVID19 was that the item of "regulations taken by the government is enough to combat disease." That implies that the subjects believe that the government should take much more action; such belief could be held by individuals who do not have strong self-efficacy, particularly those with low education levels or had no insurance individuals. Similar results were found in India's study in which some respondents were not sure about the government response [25,33].

\section{Limitations}

This study has several limitations that should be addressed. The sample size was small and overrepresented participants with higher education and female gender, and moderate to high income. Income and educational attainment are mostly taken as proxy measures of socioeconomic characteristics [34]; therefore, the responses may not be generalizable to all the populations. Another limitation was the use of the Internet with a smartphone or laptop to participate in the study. Thus, individuals who did not have access to the Internet and such electronic devices could not participate. Besides, the results may suffer from geographic biasedness. Self-reporting of data may also result in reporting bias; responses could have been reported based on social desirability, not the participants' actual situation. Also, participants probably searched for the correct answers before answering some of the questions, which may have inflated the score of COVID-19 knowledge; to control this bias, it was stressed by the researchers that the questionnaire was anonymously and emphasized the importance of answering questions honestly before completing the questionnaire. Further, more cross-sectional studies are unable to provide evidence on causality. Therefore, knowledge about and attitudes toward COVID-19 need to be further explored. Further studies about and attitudes toward and practices against COVID-19 should be further studied with a more extensive and randomized sample. Also, it is recommended to publish a 
methodology paper from the current data as there were tremendous efforts to collect and propose items of the tools that measure knowledge about and attitudes toward COVID19.

\section{CONCLUSIONS AND RECOMMENDATIONS}

Adequate knowledge, positive attitudes, and proper management and prevention of COVID-19 are essential to control the COVID-19 pandemic. Despite the government's efforts to make awareness about COVID-19 through different official and media channels, actively learning efforts are still required from the overall public. This study provided valuable preliminary insights into how public health initiatives can better protect the population's health during public health emergencies, like emerging COVID-19 pandemics, by establishing strategic behavioral interventions. Knowledge can play an essential role in enhancing the practice of public preventive behavior, as our findings showed that knowledge was related to attitudes. Information disseminated through health interventions to stop and control the epidemic must be supported by scientific evidence and delivered in understandable language to heighten general knowledge of the problem. It is highly recommended that public health practitioners and policymakers promote knowledge and understanding while addressing contextual factors that hinder the public's learning processes concerning health information. Broad-based insurance strategies across the uninsured population would be more likely to supply enhanced health and anticipation advantages than would "rescue" programs aimed only at the seriously ill. Thus, we propose that future research identify and monitor misconceptions about COVID-19 dispersed across communication platforms to supply accurate and evidence-based information about the disease and prevention measures.

Author contributions: All authors have sufficiently contributed to the study, and agreed with the results and conclusions. SAR developed the study's conception and design and analyzed the data, and wrote the first draft of the methods and results sections; NAA wrote the first draft of the introduction, discussion, limitations, conclusion, and recommendation, and the abstract; MTM did the critical revisions, wrote the final draft, and proofread the whole paper. SAR supervised the whole work.

Funding: The authors report that there was no funding source for the work that resulted in the article or the preparation of the article.

Acknowledgement: The researchers would like to acknowledge the input of all subjects who participated in the study.

Declaration of interest: The authors declare no conflicts of interest.

Ethical considerations and human subjects' protection: The study was approved by the Institutional Review Board of the Hashemite University- Jordan.

\section{REFERENCES}

1. Chen B, Tian E-K, He B, Tian L, Han R, Wang S, et al. Overview of lethal human coronaviruses. Signal Transduct Target Ther. 2020;5:89. https://doi.org/10.1038/s41392020-0190-2 PMid:32533062 PMCid:PMC7289715
2. World Health Organization. Statement on the second meeting of the International Health Regulations Emergency Committee regarding the outbreak of novel coronavirus (2019-nCoV): Geneva, Switzerland; 2020. Available at: https://www.who.int/news-room/detail/3001-2020-statement-on-the-second-meeting-of-theinternational-health-regulations-(2005)-emergencycommittee-regarding-the-outbreak-of-novel-coronavirus(2019-ncov)

3. Helmy YA, Fawzy M, Elaswad A, Sobieh A, Kenney SP, Shehata AA. The COVID-19 pandemic: A comprehensive review of taxonomy, genetics, epidemiology, diagnosis, treatment, and control. J Clin Med. 2020;9(4):1225. https://doi.org/10.3390/jcm9041225 PMid:32344679 PMCid:PMC7230578

4. Benksim A, Ait Addi R, Cherkaoui M. Vulnerability and fragility expose older adults to the potential dangers of COVID-19 pandemic. Iran J Public Health. 2020;49(suppl 1):122-4. https://doi.org/10.18502/ijph.v49is1.3682

5. Lee $M$, Kang B-A, You M. Knowledge, attitudes, and practices (KAP) toward COVID-19: a cross-sectional study in South Korea. BMC public health. 2021;21:295. https://doi.org/10.1186/s12889-021-10285-y PMid:33546644 PMCid:PMC7863060

6. Zhao W, Zhang J, Meadows ME, Liu Y, Hua T, Fu B. A systematic approach is needed to contain COVID-19 globally. Sci Bull (Beijing). 2020;65(11):876-8. https://doi.org/10.1016/j.scib.2020.03.024 PMid:32296594 PMCid:PMC7156212

7. Jordanian Ministry of Health. COVID-19 in Jordan 2020. Available at: https://corona.moh.gov.jo/ar

8. Jordanian Ministry of Health. Daily report related to COVID19 in Jordan 2021. Available at: https://corona.moh.gov.jo/ar/MediaCenter/2573

9. Rahman A, Sathi NJ. Knowledge, attitude, and preventive practices toward COVID-19 among Bangladeshi internet users. Electron J Gen Med. 2020;17(5):em245. https://doi.org/10.29333/ejgm/8223

10. Demirdover C. COVID-19 vaccines. Turk J Plast Surg. 2021;29(1):1-4. https://doi.org/10.4103/1300-6878.305908

11. Liu C, Zhou Q, Li Y, Garner LV, Watkins SP, Carter LJ, et al. Research and development on therapeutic agents and vaccines for COVID-19 and related human coronavirus diseases. ACS Cent Sci. 2020;6(3):315-31. https://doi.org/10.1021/acscentsci.0c00272 PMid:32226821 PMCid:PMC7094090

12. Al Sharif $O$. Under nationwide curfew, Jordanians now ponder economic cost of coronavirus. In: AlMonitor, The Pulse of the Middle East 2020. Available at: https://www.almonitor.com/pulse/originals/2020/03/jord an-lockdown-economy-measures-coronavirus.html

13. Iqbal MA, Younas MZ. Public knowledge, attitudes, and practices towards COVID-19 in Pakistan: A cross-sectional study. Child Youth Serv Rev. 2021;120:105784. https://doi.org/10.1016/j.childyouth.2020.105784 PMid:33311825 PMCid:PMC7718774

14. Gao H, Hu R, Yin L, Yuan X, Tang H, Luo L, et al. Knowledge, attitudes and practices of the Chinese public with respect to coronavirus disease (COVID-19): an online crosssectional survey. BMC public health. 2020;20(1816 (2020)):1-8. https://doi.org/10.1186/s12889-020-09961-2 PMid:33256707 PMCid:PMC7702204 
15. Manjate JLS, Chavane FS, Martins HR, Nhantumbo LL. Knowledge, attitudes and practices of Mozambican public employees on the prevention of Covid-19. Rev Prod Desenv. 2020;6 e446. https://doi.org/10.32358/rpd.2020.v6.446

16. Thaker J. Planning for a COVID-19 vaccination campaign: The role of social norms, trust, knowledge, and vaccine attitudes. Unpublished work - Preprint unreviewed paper 2020. https://doi.org/10.31234/osf.io/q8mz6

17. Abdel Wahed WY, Hefzy EM, Ahmed MI, Hamed NS. Assessment of knowledge, attitudes, and perception of health care workers regarding COVID-19, a cross-sectional study from Egypt. J Community Health. 2020;45(6):124251. https://doi.org/10.1007/s10900-020-00882-0 PMid: 32638199 PMCid:PMC7340762

18. Zhong B-L, Luo W, Li H-M, Zhang Q-Q, Liu X-G, Li W-T, et al. Knowledge, attitudes, and practices towards COVID-19 among Chinese residents during the rapid rise period of the COVID-19 outbreak: a quick online cross-sectional survey. International journal of biological sciences. 2020;16(10):1745-52. https://doi.org/10.7150/ijbs.45221 PMid:32226294 PMCid:PMC7098034

19. Elayeh E, Aleidi SM, Ya'acoub R, Haddadin RN. Before and after case reporting: A comparison of the knowledge, attitude and practices of the Jordanian population towards COVID-19. Plos one. 2020;15(10):e0240780. https://doi.org/10.1371/journal.pone.0240780 PMid:33057382 PMCid:PMC7561125

20. Sharaydih R, Abuloha S, Wazaify M. Promotion of appropriate knowledge and attitude towards medicines among schoolchildren in Jordan: the role of teachers. Int J Pharm Pract. 2020;28(1):84-91. https://doi.org/10.1111/ ijpp.12582 PMid:31573122

21. Alhajjaj AH, Aldarweesh $\mathrm{HH}$, Alghawi ZA. Knowledge, attitude, and awareness related to COVID-19 pandemic among the public, Saudi Arabia: A cross-sectional descriptive study. European J Med Ed Te. 2020;13(3):em2013. https://doi.org/10.30935/ejmets/8488

22. Department of Statistics-Jordan. Estimated population of the Kingdom by sex, age group and sex ratio of 2020 . PxWeb. In: Interactive database 2021. Available at: http://dosweb.dos.gov.jo/DataBank/Population_Estimare s/PopulationEstimates.pdf

23. Assaf AM, Hammad EA, Haddadin RN. Influenza vaccination coverage rates, knowledge, attitudes, and beliefs in Jordan: a comprehensive study. Viral Immunol. 2016;29(9):516-25. https://doi.org/10.1089/vim.2015.0135 PMid:27509083

24. Ahmed S, Ali MM, Hasan J. Knowledge, Attitudes, Practices and Perceptions on COVID-19 among University Students in Bangladesh. Journal of Contemporary Studies in Epidemiology and Public Health. 2021;2(1):ep21003. https://doi.org/10.30935/jconseph/9366

25. Karim A, Akter M, Mazid A, Pulock OS, Aziz TT, Hayee S, et al. Knowledge and attitude towards COVID-19: A cross sectional study in Bangladesh through phone and online survey. J Clin Exp Invest. 2020;11(4):em00757. https://doi.org/10.29333/jcei/9143
26. Roy D, Ghosh TK, Saha M, Sarker S. Assessing knowledge, attitude, and practice towards COVID-19 among sub assistant agriculture officers: An empirical study in Bangladesh. Journal of Contemporary Studies in Epidemiology and Public Health. 2020;1(2):ep20009. https://doi.org/10.30935/jconseph/9364

27. Alnasser AHA, Al-Tawfiq JA, Al-Kalif MSH, Shahadah RFB, Almuqati KSA, Al-Sulaiman BSA, et al. Public Knowledge, Attitudes, and Practice towards COVID-19 Pandemic in Saudi Arabia: A Web-Based Cross-Sectional Survey. Med Sci (Basel). 2021;9(1):11. https://doi.org/10.3390/medsci90100 11 PMid:33669208 PMCid:PMC7931095

28. Institute of Medicine (US) Committee on the Consequences of Uninsurance [press release]. Washington (DC): National Academies Press (US)2002.

29. Lee M, You M. Psychological and behavioral responses in South Korea during the early stages of coronavirus disease 2019 (COVID-19). Int J Environ Res Public Health. 2020;17(9):2977. https://doi.org/10.3390/ijerph17092977 PMid:32344809 PMCid:PMC7246607

30. Abdelhafiz AS, Mohammed Z, Ibrahim ME, Ziady HH, Alorabi $M$, Ayyad M, et al. Knowledge, perceptions, and attitude of Egyptians towards the novel coronavirus disease (COVID19). J Community Health. 2020;45:881-90. https://doi.org/ 10.1007/s10900-020-00827-7 PMid:32318986 PMCid: PMC7173684

31. Lau LL, Hung N, Go DJ, Ferma J, Choi M, Dodd W, et al. Knowledge, attitudes and practices of COVID-19 among income-poor households in the Philippines: A crosssectional study. J Glob Health. 2020;10(1):011007. https://doi.org/10.7189/jogh.10.011007 PMid:32566169 PMCid:PMC7294392

32. Al Demour S, Ababneh MA, Al-Taher RN, Alrabadi AF, Jaradat AF, Abushamma FA, et al. Knowledge, practice, and attitude toward COVID-19 among physicians in Jordan and Palestine: Cross-sectional study. Int J Gen Med. 2021;14:7787. https://doi.org/10.2147/IJGM.S294221 PMid:33469347 PMCid:PMC7812038

33. Yousaf MA, Noreen M, Saleem T, Yousaf I. A cross-sectional survey of Knowledge, Attitude, and Practices (KAP) toward pandemic COVID-19 among the general population of Jammu and Kashmir, India. Soc Work Public Health. 2020;35(7):569-78. https://doi.org/10.1080/19371918.2020. 1806983 PMid:32970548

34. Zhong B-L, Chen S-L, Tu X, Conwell Y. Loneliness and cognitive function in older adults: Findings from the Chinese longitudinal healthy longevity survey. J Gerontol B Psychol Sci Soc Sci. 2017;72(1):120-8. https://doi.org/10. 1093/geronb/gbw037 PMid:27013536 PMCid:PMC5156491

35. Karijo E, Wamugi S, Lemanyishoe S, Njuki J, Boit F, Kibui V, et al. Knowledge, attitudes, practices, and the effects of COVID-19 on health seeking behaviors among young people in Kenya. Preprint. 2020. https://doi.org/10. 21203/rs.3.rs-34861/v3 PMid:34053442 PMCid:PMC8164891 